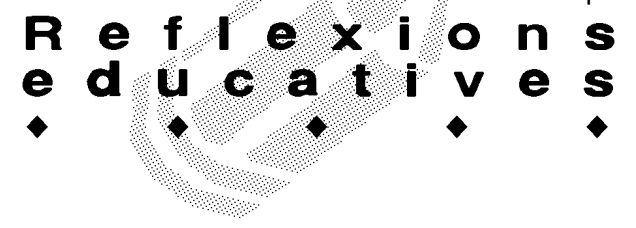

\title{
PSICOMOTRICITAT: INTERACCIÓ ENTRE EDUCACIÓ ESPECIAL I EDUCACIÓ INFANTIL
}

\author{
Isabel Viscarro Tomás. Àrea de Didàctica de l'Expressió Corporal \\ Cori Camps Llauradó. Àrea de Psicologia Educativa i de l'Educació \\ Mercè Rota Iglesias. Mestra i psicomotricista del CEE "Estela"
}

\section{Procés de col-laboració entre els professionals de les institucions implicades \\ Aquesta experiència d'integració va sorgir després} d'un procés de col-laboració entre les tres institucions implicades:

En primer lloc, la col-laboració entre el CEE "Estela" $i$ el CEIP de Pràctiques, dos centres molt propers dins la zona educacional de Tarragona, es va iniciar fa vuit anys amb l'objectiu prioritari "d'obrir les portes" per donar a tots els nens l'oportunitat d'ampliar el seu món de relació, afecte, respecte i convivència. Posteriorment ens hem anat introduint també en alguns aprenentatges. En un començament compartíem una part del temps de lleure. Després la relació es va ampliar amb activitats més específiques: música i dansa, festes populars, jocs, tallers de matemàtiques i plàstica, sortides, etc. Durant aquests anys hi ha hagut la integració escolar a temps parcial, al CEIP Pràctiques, de diferents nens i nenes amb algun tipus de dèficit. Fa tres cursos vam iniciar l'activitat psicomotriu que després explicarem.

Paral-lelament, i per una llarga tradició, hi ha un acord de col-laboració institucional entre el CEIP de Pràctiques i la Facultat de Ciències de l'Educació i Psicologia, que es remunta a quan l'Escola Annexa era el principal centre de pràctiques per als alumnes de l'Escola de Magisteri de Tarragona.

Concretament, en l'àrea de psicomotricitat en Educació Infantil, el curs 1991-92 ens vam plantejar la possibilitat d'iniciar una experiència conjunta entre els cursos de parvulari amb el psicomotricista i una professora de l'ensenyament de Mestres de la Facultat. El curs 1995-96 vam ampliar el grup de professionals amb la incorporació d'una professora de l'ensenyament de Psicologia, amb experiència en aquest àmbit; completant el grup de persones amb un alumne, també de Psicologia.

Al mateix temps, a partir del curs 1995-96 formem un grup de treball de l'ICE, amb els professionals ja citats, les mestres de parvulari del CEIP de Pràctiques $\mathrm{i}$ la psicomotricista del CEE "Estela", amb la finalitat de connectar les sessions de psicomotricitat amb la programació d'aula.

Creiem que és molt enriquidora, tant per a nosaltres (adults participants) com per als grups de nens i nenes, la visió de professionals de diferents àmbits educatius.

L'experiència que us presentem és un projecte comú elaborat pels especialistes de les tres institucions, en el marc de la Pràctica Psicomotriu de Bernard Aucouturier, ja que creiem que és un marc idoni, facilitador de l'experiència d'integració entre els nens i nenes dels dos centres educatius.

\section{Objectius de l'experiència}

Els objectius són per a tots els nens, tot i que els primers van més dirigits als alumnes de l'Escola Especial i els darrers als nens de l'ordinària (on també hi ha alguns nens amb dèficit):

- Afavorir la pròpia experimentació psicomotriu en un espai diferent de l'habitual, més ric en materials, recursos i possibilitats d'acció.

- Facilitar el joc motriu al costat dels altres nens i nenes del grup, l'observació, la imitació i, si pot ser, la comunicació i la convivència, tot treballant també les actituds.

- Facilitar l'autonomia progressiva del nen vers el "seu» adult de referència, i ajudar-lo a obrir-se als altres mestres que col-laboren en la sessió.

- Obrir els nens-es a la comunicació i ajudar-los a l'acceptació de la diversitat. Tots no som iguals, i volem educar per aprendre a conviure i a acceptar i respectar les diferències.

\section{Valoració de l'experiència}

En relació als nens amb déficit hi ha:

- il-lusió i ganes d'anar al gimnàs de «l'altra» escola,

- conductes semblants a les que es donen a l'escola d'educació especial, però més motivació vers l'activitat, - moments d'apropament entre ells (fet no tan habitual 


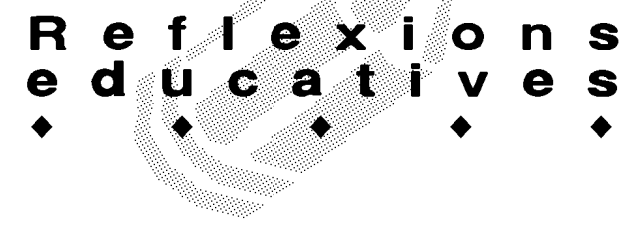

quan són dins l'escola d'educació especial),

- per part d'alguns d'ells, imitació de l'activitat motriu dels nens de l'escola ordinària,

- dificultat per marxar del gimnàs en acabar-se la sessió.

En relació als nens de l'escola ordinaria hem observat:

- la importància de «deixar-los dir» tot el que viuen en relació:

- al rebuig que poden sentir

- a les discapacitats dels altres que els criden l'atenció - a les conductes agressives, d'inhibició, provocació, etc, que veuen per part dels nens amb dèficit, aprofitant a l'hora per reflexionar que, a vegades, ells també les tenen - la necessitat d'ajudar-los a acceptar i no culpabilitzar la negativitat vers la diferència per tal de poder començar a canviar

- que es van donant moments diversos de protecció, rebuig, acolliment...

- que els nens de l'escola ordinària que presenten conductes «difícils» són els que tenen més conflicte en la relació amb els nens de l'escola d'educació especial - que els nens amb dèficit de l'escola ordinària mostren especial predilecció per estar prop dels nens i l'adult de l'escola especialitzada.

En relació a "tots els nens" veiem:

- la importància de la verbalització, la comprensió i la reflexió vers els conflictes i les dificultats,

- l'oportunitat de poder experimentar que tots no som iguals i que hem de procurar conviure i respectar-nos,
- l'especial adequació de la Pràctica Psicomotriu als objectius que pretenem.

Per part dels psicomotricistes:

- Des de l'escola d'educació especiales veu:

- la necessitat de mobilitzar més l'atenció, la cura de les actituds, la manera de situar-se, etc., donat el canvi d'espai, material, nens..., fet que estimula i ajuda a reflexionar i a superar-se (no és tan còmode com «quedar-se a casa»),

- que es donen més recursos per fer evolucionar les actituds dels nens amb dèficit: material divers, jocs, imitació dels altres...

- Des de l'escola ordinària es veu:

- que en un principi hi havia una sensació de repte i inseguretat davant el desconeixement del treball amb nens-es amb dèficit, fet que es reflectia en un «no saber gaire què fer",

- que el contacte amb aquests nens i l'observació de l'actitud cap a ells de la seva psicomotricista ens ha facilitat poder-nos situar amb més seguretat davant la intervenció en la diversitat,

- que tant la col-laboració entre els adults que intervenim en les sessions com el treball amb tots els nens són enriquidors i eviten l'estancament d'actituds i relacions.

A nivell general, volem remarcar que el fet de valorar positivament l'activitat no vol dir que sigui un «treball fàcil» i que, tots plegats, encara som en un procés d'aprenentatge.

Esperem més endavant poder oferir uns resultats $i$ una valoració més específics i concrets.

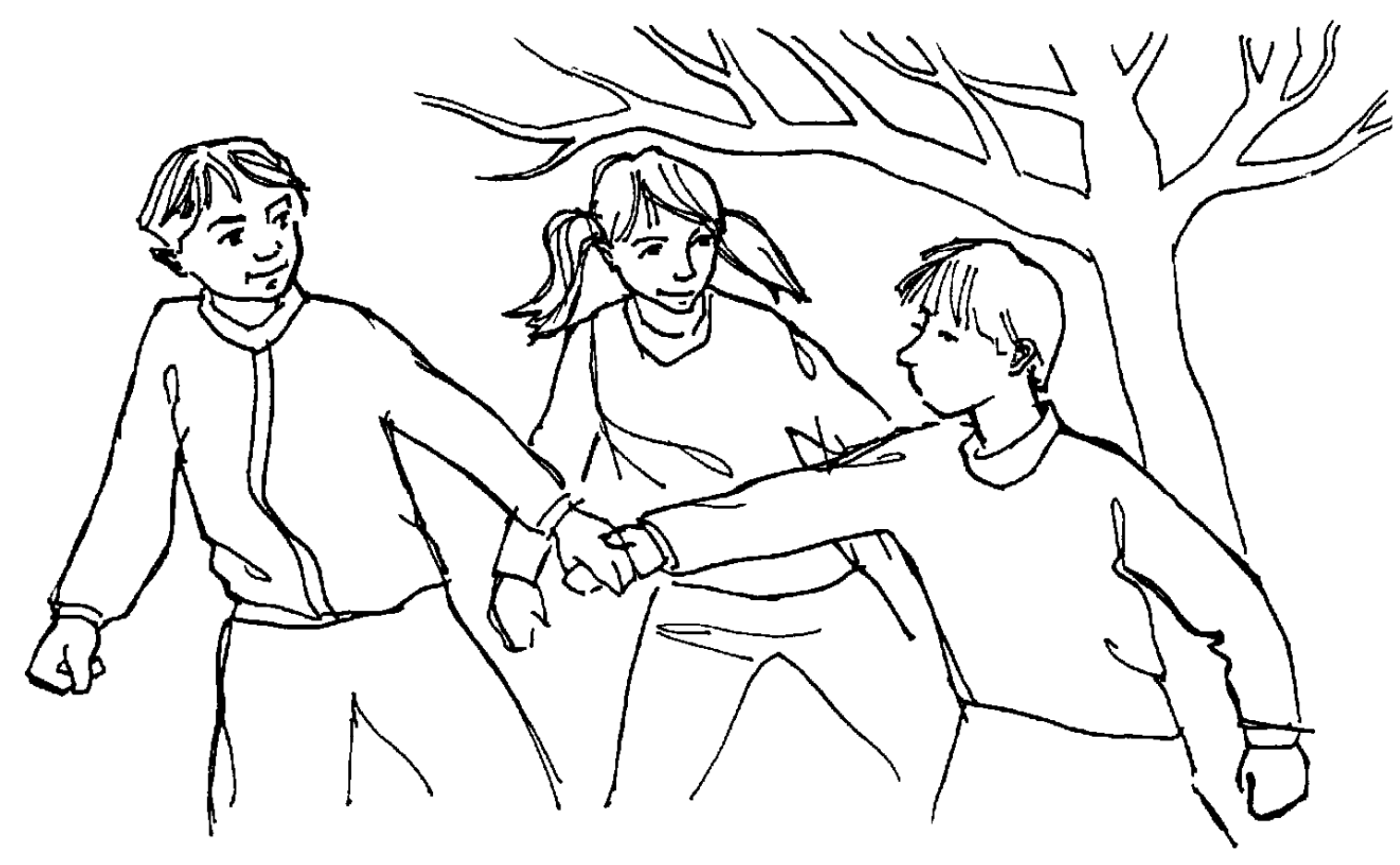

